\title{
Contenido y calidad de las imágenes de observación terrestre
}

\section{Earth observation image information content and quality}

\author{
Avid Roman-Gonzalez ${ }^{1}$, Natalia Indira Vargas-Cuentas ${ }^{2}$ \\ ${ }^{1}$ TELECOM ParisTech, 46 rue Barrault, 75013 - Paris, Francia \\ ${ }^{2}$ Escuela Militar de Ingeniería - EMI, La Paz, Bolivia
}

\begin{abstract}
Resumen
En el presente artículo describiremos la extracción de información de imágenes satelitales y la importancia de la calidad de las imágenes satelitales. Indagaremos con más detalle en el ámbito de los artefactos y su influencia en la extracción de información de las imágenes satelitales. En un sistema de teledetección, si bien, las imágenes son muy importantes, pero lo más importante es la información que podemos extraer de ellas para interpretar y aplicar esta información en diferentes campos. En ese sentido, la calidad de imagen juega un papel importante. Si queremos obtener la mayor e importante cantidad de información de una imagen, es necesario que la imagen tenga una buena calidad. El principal objetivo de cualquier sistema de teledetección es el uso de la información que se puede extraer de las imágenes, esto incluye la detección, medición, identificación e interpretación de diferentes objetivos de interés. Los objetivos de interés en imágenes de teledetección pueden ser cualquier característica, objeto, textura, forma, estructura, espectro o cobertura superficial que están en la imagen. El proceso de un sistema de teledetección y análisis puede ser realizado manualmente o de manera automática, en realidad, hay muchos grupos de investigación que desarrollan diferentes herramientas para detectar, identificar, interpretar y extraer información de los objetivos de interés sin intervención manual de un intérprete humano.
\end{abstract}

Descriptores: teledetección, imágenes satelitales, detección de artefactos, calidad de las imágenes

\begin{abstract}
In this article we will describe the information extraction from satellite image, the importance of image quality in satellite image. In this paper we will study in more detail the artifacts and their influence on the information extraction from satellite images. In a remote sensing system, although, the images are very important, but more important is the information that we can extract from them to interpret and apply this information in different fields. In this sense, the image quality plays an important role. If we want to get the biggest and most important amount of information from the image, we need to have a good image quality. The main objective of any remote sensing system is the use of information that we can extract from the images, this includes detection, measurement, identification and interpretation of different targets. Targets in remote sensing images may be any feature, object, texture, shape, structure, spectrum or land covers which are in the image. Remote sensing process and analysis could be performed manually or automatically, actually, there are many research groups that develop different tools for detect, identify, extract information and interpret targets without manual intervention by a human interpreter.
\end{abstract}

Keywords: remote sensing, satellite images, artifacts detection, image quality

\section{Introducción}

Para extraer la información contenida en las imágenes satelitales, es necesaria la extracción de diferentes características tales como: el color, la textura o la forma.
Para extraer información de una imagen satelital para el análisis, clasificación, indexación, segmentación, etc., la característica de color puede ser utilizada. El color está en función de la información espectral a través de su representación numérica. La idea es identificar cada píxel en función de la información espectral para una o más bandas 
espectrales. Un análisis basado en características de la firma espectral tiene el mismo principio, pero en este caso, todas las bandas espectrales son utilizadas.

Otra forma de extraer información de una imagen es utilizando la textura. En general, la textura se define como un segmento con propiedades 0 características homogéneas, es una repetición de motivos que crean una imagen visualmente homogénea manteniendo su relación espacial. A partir de estas definiciones, las investigaciones en este campo se dirigen a caracterizar estas relaciones espaciales [1]. Por ejemplo, [2] se utilizaron medidas estadísticas para discriminar las diferentes estructuras en una imagen, proponiendo 14 características calculadas a partir de una matriz de co-ocurrencia correspondiente a las estadísticas de segundo orden.

La extracción de información de imagen usando las formas geométricas se basa en la extracción de características geométricas tales como el área, la excentricidad del eje de longitud, el impulso algebraico invariante, etc. Estas características se utilizan para implementar el primer conjunto de búsqueda de imágenes por contenido.

Es posible también combinar y mezclar color, espectro, la textura y las características geométricas para el proceso de análisis de una imagen satelital.
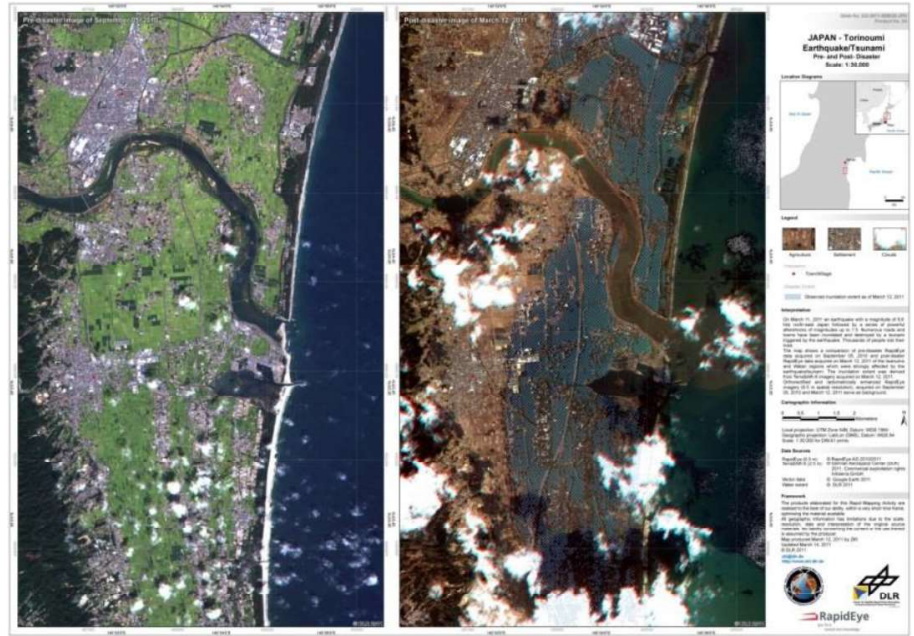

Figure 1: Ejemplo de aplicación y análisis de imágenes de teledetección [International charter Space and major Disaster].

Después del proceso de extracción de características, la siguiente etapa es la etapa de clasificación, para la clasificación es posible utilizar dos enfoques: la clasificación supervisada o clasificación no supervisada.
La clasificación supervisada necesita un conjunto de datos para una etapa previa de entrenamiento, es necesaria una buena selección del conjunto de datos para entrenamiento, este conjunto debe ser pertinente y apropiado para obtener buenos parámetros como resultado. Estos parámetros que son el resultado de la etapa de entrenamiento se utilizan para la clasificación final de los datos restantes.

La clasificación no supervisada no necesita una etapa de entrenamiento. Este tipo de clasificación utiliza directamente algoritmos de agrupamiento para determinar los grupos naturales de los datos. Depende del tipo de algoritmo para determinar qué característica será la más predominante para el agrupamiento, ya sea el color, espectro, textura o forma. En la mayoría de los casos es necesario especificar el número de grupos de datos, el parámetro de distancia, etc.

Cualquiera sea el tipo de clasificación utilizado, el resultado final del proceso de análisis, es un mosaico de píxeles o patches en los que cada uno representa una categoría de las características de interés que se está analizando, el resultado es un mapa de la imagen original.

\section{Calidad de las imágenes de observación terrestre}

Una imagen satelital debe ser capaz de responder a las necesidades de los usuarios finales, por lo tanto la calidad requerida de la imagen dependerá del tipo de aplicación, por ejemplo podría ser una aplicación de análisis de interpretación de fotografías tal como se muestra en [3], con aplicaciones en las áreas de monitoreo de bosques y vigilancia de la deforestación, el seguimiento y monitoreo de las tierras agrícolas, la meteorología, el color del agua, la vigilancia de los desastres naturales (terremotos, inundaciones, etc), la defensa, etc. los diferentes parámetros requeridos dependerán también del tipo de aplicación.

En general existen algunos criterios para evaluar la calidad de una imagen satelital en tres ámbitos importantes:

- Geométrico.

- Radiométrico.

- En relación con la resolución. 
En el dominio geométrico de las imágenes, existe un tema interesante el cual es precisar la posición de los pixeles; los criterios que definen la calidad de la imagen deben ser capaces de evaluar la alteración de longitudes, la superposición de las bandas y la precisión de la altimetría.

En el dominio asociado con la radiometría el tema importante es el valor de cada pixel, los criterios que se evaluarán en este dominio son: El ruido radiométrico, la precisión de la calibración, etc.

En el dominio relacionado con la resolución los criterios importantes son la capacidad del sistema y la percepción de los detalles, por otra parte los temas que deben ser tomados en cuenta para la evaluación de la calidad son: La toma de muestras, la función de transferencia de modulación, etc.

Dichos criterios para evaluar la calidad de una imagen satelital, en efecto sirven para definir las necesidades de los usuarios y para definir las especificaciones de los diferentes componentes para el proyecto espacial de observación del planeta Tierra

\section{Artefactos en imágenes de observación terrestre}

Los artefactos son estructuras artificiales que representan una perturbación estructurada de la señal, por lo tanto estos artefactos inducirán errores en la indexación de las imágenes.

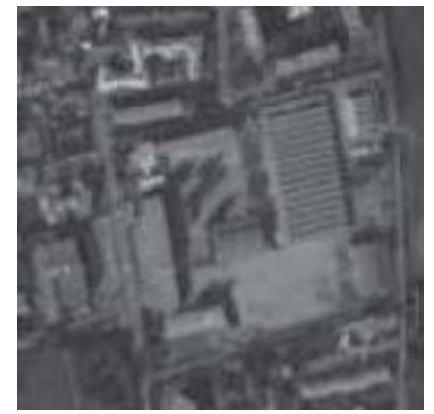

(a)

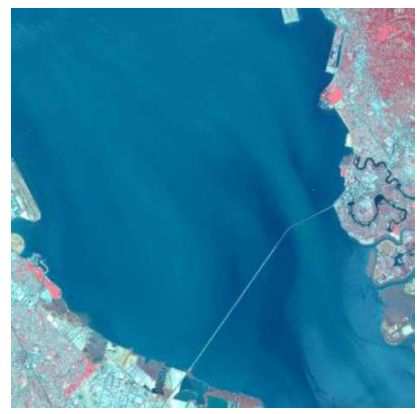

(c) SPOT

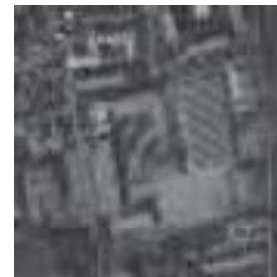

(b)

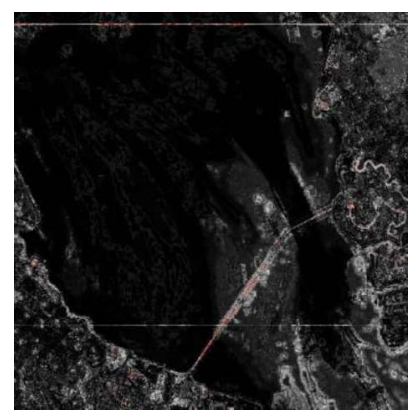

(d)

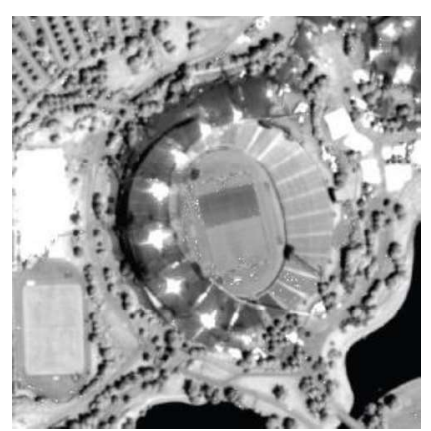

(e) IKONOS

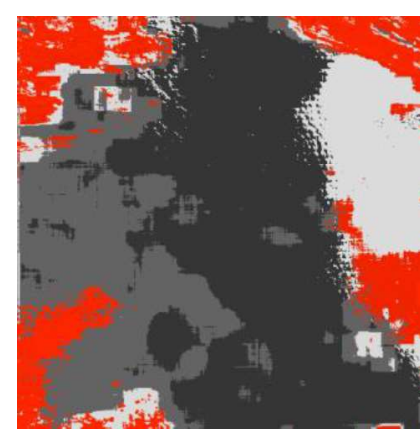

(f) MERIS
Figure 2: Algunos ejemplos de artefactos: (a) y (b) muestra un cambio de textura por "aliasing". (c) muestra una imagen del mar donde hay un puente. (d) muestra la existencia de líneas horizontales y estas líneas pueden ser detectadas como puentes por un algoritmo de indexación. (e) muestra la saturación del sensor. (f) muestra el bloqueo en la imagen.

La Figura 2 muestra algunos ejemplos de artefactos, en (a) y (b) se puede observar un cambio de textura, (c) y (d) nos muestran la existencia de líneas horizontales que pueden ser detectadas como puentes; en (e) podremos observar saturación del sensor y (f) nos muestra problemas de creación de bloques característico de un proceso de compresión. Todos los procesos mencionados anteriormente pueden verse afectados si la imagen tiene artefactos, estos artefactos pueden interferir con el reconocimiento de una textura o la cuantificación de una característica. La naturaleza de algunos de estos artefactos es desconocida y variable, estos artefactos no poseen los mismos modelos, es por eso que es necesario implementar métodos capaces de detectar estos artefactos, independientemente del modelo que se forman, es decir un método libre de parámetros.

En esta parte del artículo se presentan y describen con más detalle algunos artefactos específicos reales encontrados en imágenes satelitales. En la Figura 3 (a) se muestra un defecto de línea intermitente en una imagen SPOT, este defecto es una pérdida de señal electrónica durante el proceso de formación de la imagen que genera una saturación aleatoria del sensor. Esta intermitencia consiste en falta de información y aparecen como pequeñas áreas blancas en la imagen.

En la Figura 3 (b) y (c) podemos observar problemas de saturación, la saturación se produce cuando el sensor alcanza su capacidad máxima para el valor requerido, esto conduce a una pérdida de información, ya que no se podrá medir el valor 
verdadero, dicha saturación produce un desplazamiento de saturación, ya que los píxeles adyacentes también estarán saturados. Este problema de la saturación desplazada se produce cuando el sensor es del tipo barra, ya que la adquisición de la imagen se realiza mediante el desplazamiento del satélite, de manera que un sensor que pertenece a la barra formará una columna completa de la imagen. Por otro lado si se utiliza un sensor de matriz, cada píxel sería un sensor y no se produciría ningún problema.

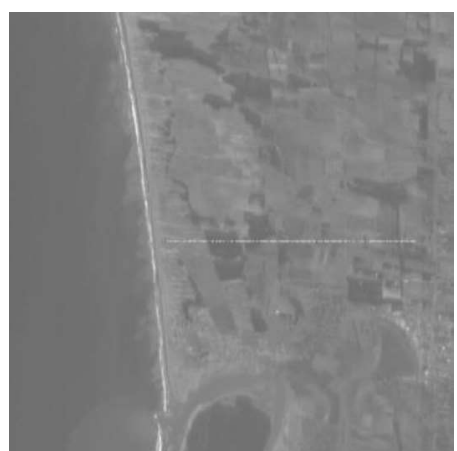

(a) Dropout (SPOT)

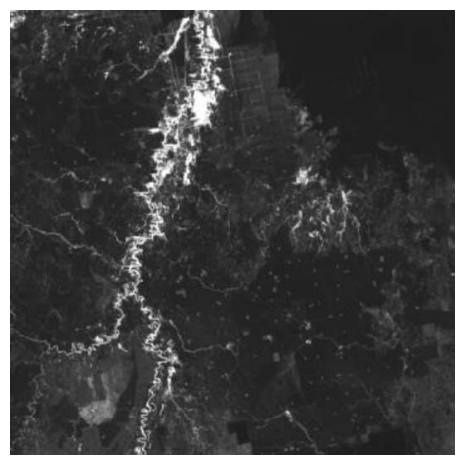

(c) Saturation

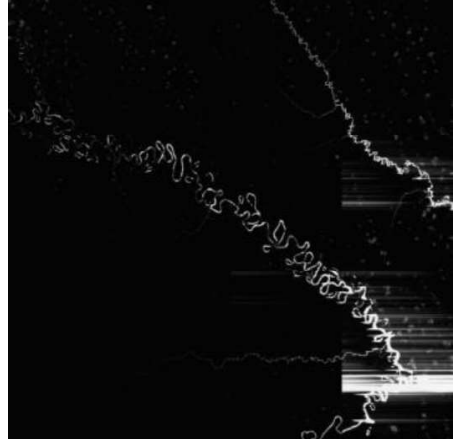

(b) Defects and saturation

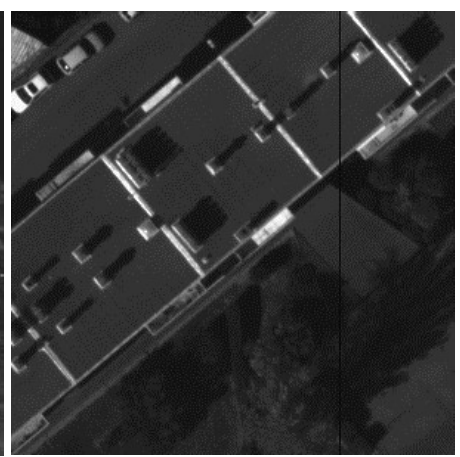

(d) Dead line
Figura 3: Algunos ejemplos de la base de datos real: (a) Dropout (SPOT) (b) Defectos. (c) Muestra la saturación del sensor. (d) Muestra la existencia de la línea muerta vertical.

En la Figura 3 (d) se puede apreciar la presencia de una columna vertical muerta, este defecto se produce debido a que el detector no está operando (detector muerto), por lo que tenemos que no se está capturando la señal y se está enviando siempre cero "0" como valor de la información, de modo que hay un punto negro que posteriormente se convertirá en una línea negra, debido al desplazamiento del satélite durante la formación de la imagen, de nuevo se produce este problema cuando el sensor es un sensor tipo barra. Si se utiliza un sensor de tipo matriz, la presencia de un "detector muerto" se refleja por la presencia de un punto negro en la imagen.

En el proceso de elaboración del producto estándar de una imagen satelital, hay un proceso de corrección de artefactos tal como se presenta en [4], que es un algoritmo para la restauración de líneas defectuosas, sin embargo algunos artefactos pueden permanecer después de este proceso.

\section{Impacto de los Artefactos en el Análisis de las Imágenes Satelitales}

Los artefactos influyen en las herramientas automáticas de análisis de imágenes como la detección de similitud, clasificación, reconocimiento de patrones, etc. A veces, los problemas de calidad están presentes, una cierta distorsión inesperada o estructuras artificiales llamados "artefactos" que pueden hacer más difícil el análisis de las imágenes y pueden disminuir la eficiencia del proceso de clasificación; pero exactamente no sabemos cómo la presencia artefactos afecta al análisis de las imágenes. En esta sección del artículo se presenta una evaluación sobre la variación de la clasificación debido a la presencia de artefactos en las imágenes satelitales. Para hacer dicha evaluación usamos diferentes procesos de extracción de características tales como características basadas en Gabor Wavelet presentadas en [5], usamos también características basadas en Quadrature Mirror Filter (QMF) utilizado en [6], y las características basadas en la Matriz de Co-ocurrencia [7]. Las características de Gabor Wavelets se basan en el principio de cálculo de la producción de energía promedio para cada filtro, este análisis utiliza los componentes espaciales y de frecuencia para analizar las diferencias entre texturas. El resultado es una respuesta directa de la descomposición de la imagen original en varias imágenes filtradas con información espectral limitada, que se utiliza para la extracción de simples características estadísticas de los valores de escala de grises de las imágenes filtradas.

En un banco $Q M F$, las señales reconstruidas tienen diferencias con la señal original, esto debido a la generación de aliasing, que es una distorsión en la amplitud y la fase. Para la implementación de un banco QMF se utiliza un par de filtros paralelos seguidos por sub-muestreadores, las señales resultantes son normalmente cuantificados y codificados utilizando un codificador de entropía para entonces poder ser transmitidas y por el lado del receptor se tienen los decodificadores combinados con bloques de sobre muestreo y dos filtros de reconstrucción. 
La matriz de co-ocurrencia describe la frecuencia de un nivel de gris que aparece en una relación espacial específica con otro valor de gris dentro del área de una ventana en particular. La matriz de coocurrencia es un resumen de cómo los valores de los píxeles se producen junto a otro valor en una pequeña ventana.

En la Figura 4 se presentan dos resultados de la clasificación de imágenes. La Figura 4 (a) nos muestra un entorno de bosque para clasificación. La Figura 4 (b) nos muestra la misma imagen de la Figura 4 (a) pero con algunos artefactos introducidos manualmente, estos artefactos son líneas defectuosas introducidas en la zona indicada por los círculos rojos. Se clasificaron las imágenes de la Figura 4 (a) y la Figura 4 (b), la clasificación se realizó en 5 clases para los tipos de bosques, podemos observar la variación en el resultado de clasificación en la Figura 4 (c) y la Figura 4 (d); esta variación representa alrededor de 4 y 5 por ciento de píxeles sólo en la zona indicada por los círculos rojos.

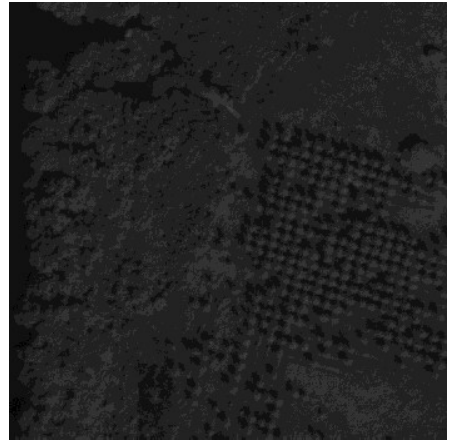

(a) Image without Artifacts

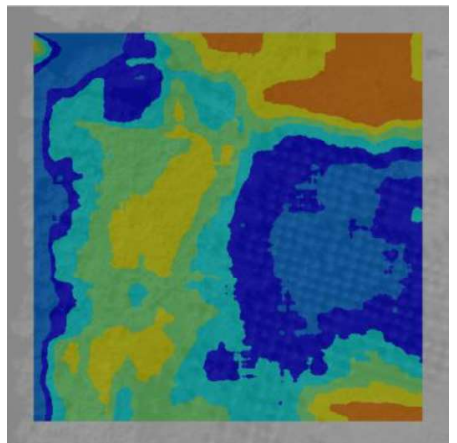

(c) Clasificación para la imagen (a)

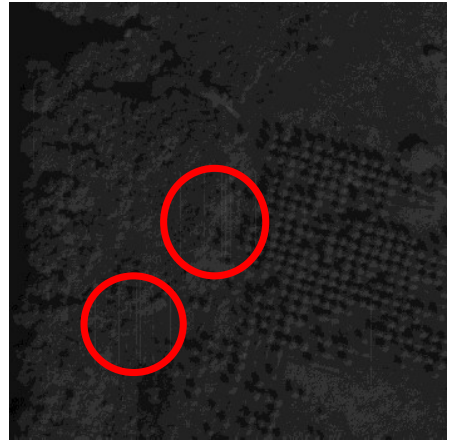

(b) Image with Artifacts

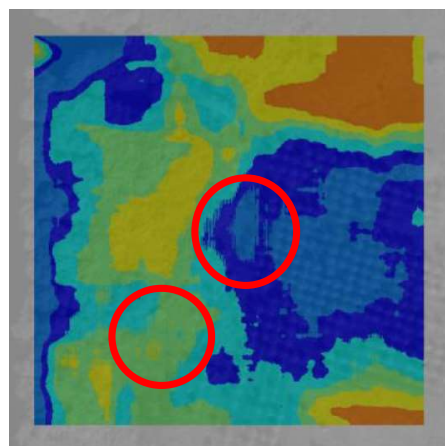

(d) Clasificación para la imagen (b)
Figure 4: Ejemplo de evaluación de artefactos.

En general, la presencia de los artefactos en la imagen satelital puede producir una variación en el proceso de clasificación o proceso de indexación; esta variación afecta a la ciudad, el bosque, el mar o las clases de entorno de campo; esta variación podría ser de alrededor del 3 o 10 por ciento y dependiendo de la aplicación, el error puede ser muy importante.

En la Figura 5 podemos ver otro ejemplo de evaluación de cómo los artefactos afectan en el proceso de clasificación de imágenes satelitales. En este ejemplo se muestra una imagen de bosque ya clasificada, la clasificación se realizó en 3 grupos y se llevó a cabo utilizando las características QMF. Por otra parte se introducen artefactos sintéticos en la imagen, en este caso se introdujeron tiras con diferentes niveles de intensidad y después se procedió a evaluar la variación de clasificación para la intensidad de las tiras introducidas. De esta manera podemos ver que para un nivel de tiras de $k$ $=10$, hay una variación con respecto a la clasificación de la imagen original, y si vemos la clasificación de la imagen con una intensidad tiras de $k=20$, la variación es mucho mayor.
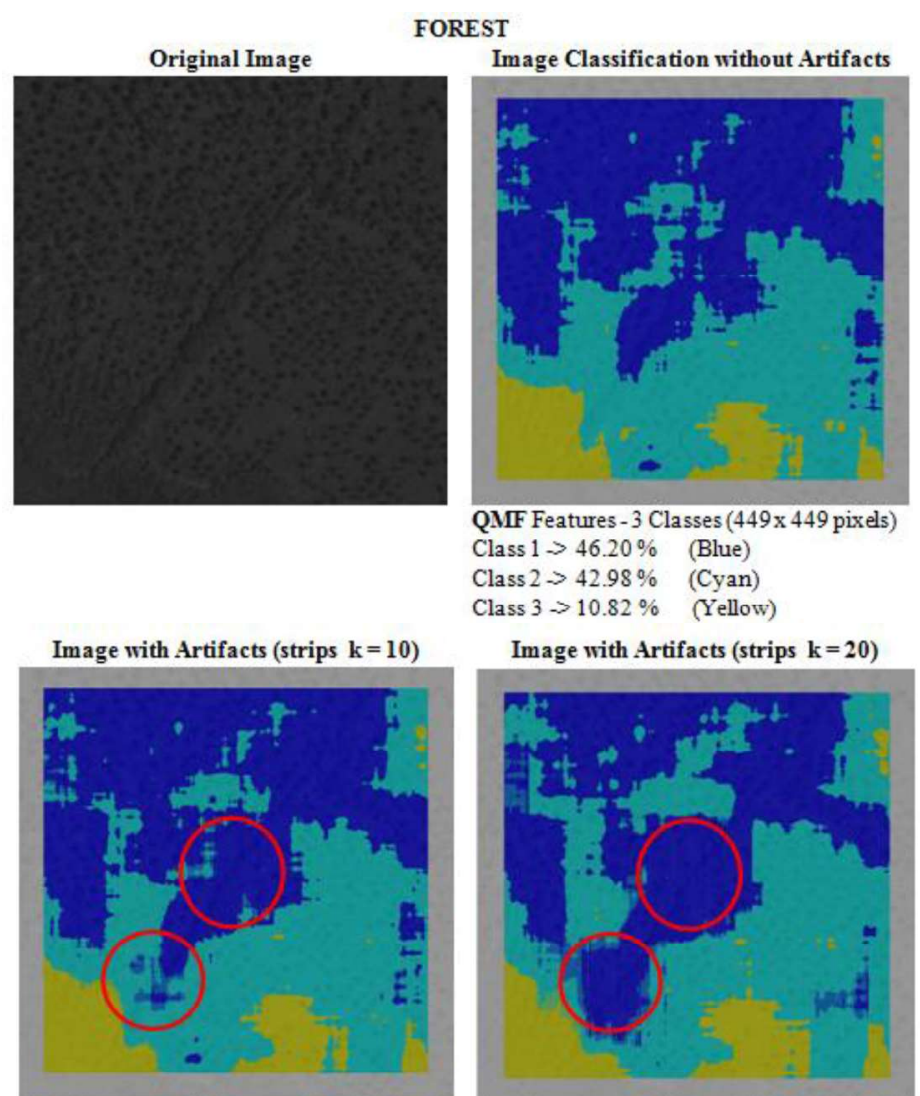

QMF Features - 3 Classes ( $449 \times 449$ pixels) Class $1>46.30 \% \quad$ (Blue) Class $2 \rightarrow 43.21 \% \quad$ (Cyan) Class $3>10.49 \% \quad$ (Yellow)

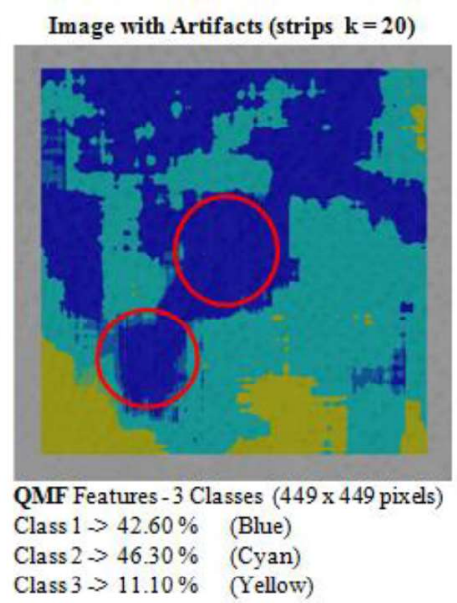

Figura 5: Evaluación de artefactos sintéticos en el medio ambiente forestal.

Podemos observar que la clasificación se realiza en 3 clases, la clase 1 para el color azul, clase 2 para el color cian y por último la clase 3 para el color 
amarillo. La clasificación de la imagen original tiene la siguiente distribución de píxeles: $46,2 \%$ para la clase 1, 42,98\% para la clase 2 y 10,82\% para la clase 3. Analizando la clasificación con la introducción de artefactos a una intensidad de $k=$ 10, la distribución es la siguiente : $46,3 \%$ para la clase $1,43,21 \%$ para la clase 2 y $10,49 \%$ para la clase 3 , lo que indica una variación de $0,66 \%$ en el total, esta variación se puede apreciar visualmente a la perfección. Por otra parte cuando tenemos una intensidad $k=20$ para el artefacto, la distribución es la siguiente: $62,6 \%$ para la clase 1 , el $46,3 \%$ para la clase 2 y $11,10 \%$ para la clase 3 , lo que representa una variación del $4 \%$ en total, lo cual representa una gran diferencia y puede llegar a afectar dramáticamente los resultados de la clasificación y la indexación de las imágenes dependiendo de la aplicación que se les dé.

Un ejemplo de la evaluación de las consecuencias que podrían traer los artefactos se muestra en la Figura 6 , en este caso es una imagen real con un artefacto real, donde se puede observar la presencia de una línea vertical, debido a la presencia de un sensor muerto. Si bien no podemos hacer una evaluación cuantitativa de cuanto la clasificación ha cambiado, debido a que no tenemos la imagen limpia, pero si podemos observar que la existencia de esta línea produce la presencia de un patrón extraño en el momento de la clasificación, como se puede ver en el círculo rojo resaltado. Para esta clasificación, se utilizó las características de filtro de Gabor y un tamaño de patch igual a 64×64 píxeles.
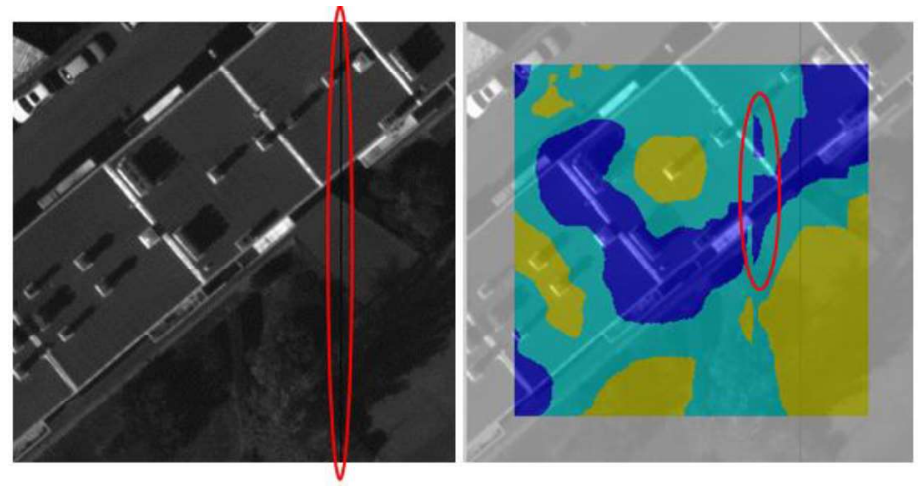

Figure 6: Evaluación de artefactos para una imagen real.

Otro ejemplo de la evaluación de las consecuencias que podrían traer los artefactos se muestra en la Figura 7, en este caso se aplica un algoritmo de segmentación de imagen sin artefactos, después de eso, se introduce una línea en la imagen simulando un artefacto y entonces se aplica el algoritmo de segmentación de imagen ya con artefacto.
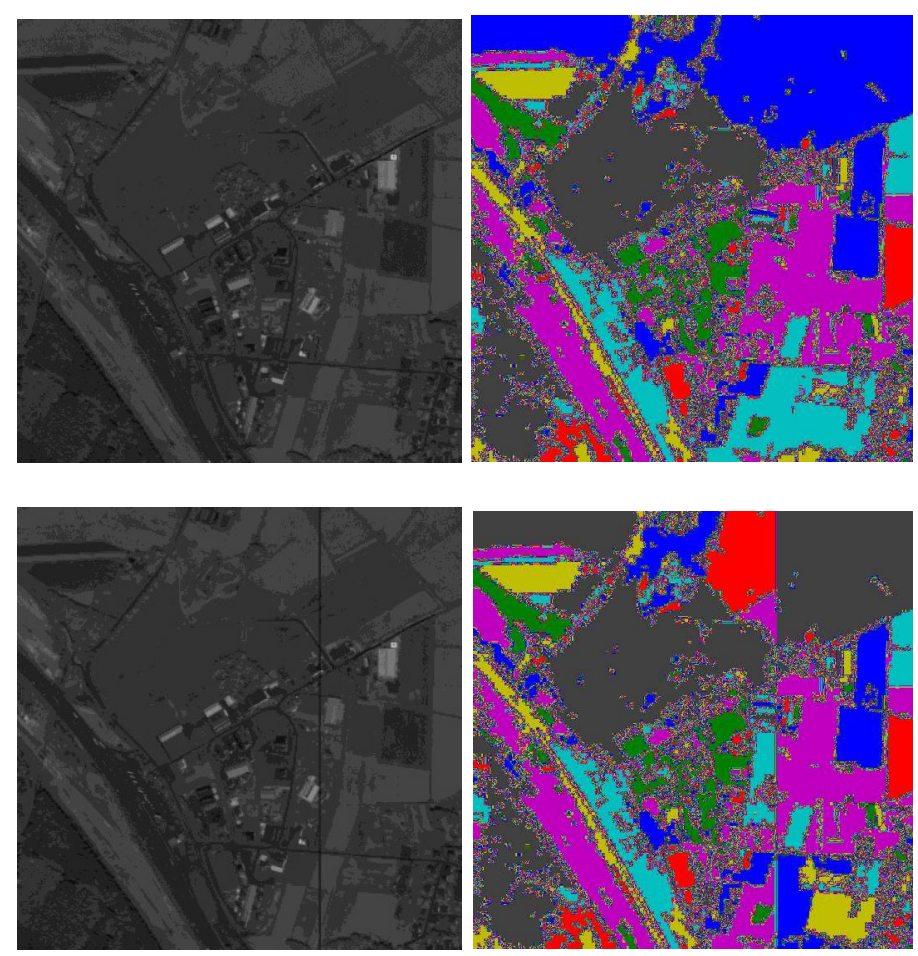

Figure 7: Evaluación de artefactos para imágenes con artefactos de línea.

Podemos ver que la presencia del artefacto cambia el resultado del algoritmo de segmentación. El algoritmo de segmentación que se utilizó fue el algoritmo de promedio de desplazamiento implementado en el software EDISON. El algoritmo "Mean-shift" es una técnica de análisis no paramétrica, de características espaciales y los dominios de aplicación incluyen la visión de agrupación por computador y el procesamiento de imágenes. EDISON es un código para la detección de bordes y sistema de segmentación de imágenes con algoritmos que son descritos en [8]

\section{Discusiones y Conclusiones}

En este artículo hemos descrito la importancia de la extracción de información de las imágenes de satelitales y la importancia de la calidad de la imagen en este proceso de extracción de información.

Hemos podido observar que la calidad de la imagen se ve afectada por la presencia de artefactos.

Hemos descrito diferentes artefactos y la influencia que tendrán en el proceso de extracción de información de las imágenes satelitales.

Debido a la variación en el proceso de clasificación, es necesario implementar métodos capaces de 
detectar la aparición de defectos tales como [4], [9], [10] y [11].

Para el mejor entendimiento de la calidad de la imagen y su degradación debido a diferentes causas, es recomendable el estudio de los campos relacionados como: la calidad de la imagen multimedia, las marcas de agua, steganalysis y la falsificación de imágenes.

\section{Referencias}

[1] L. Gueguen, (2007). Extraction d'Information et Compression Conjointes des Séries Temporelles d'Images Satellitaires, PhD. Thesis - TELECOM ParisTech

[2] R. M. Haralick, K. Shanmugan \& I. Dinstein, (1973). Textural Features for Image Classification, IEEE Transaction on System, Man and Cybernetics, vol. 6, $\mathrm{N}^{\circ} 3$, pp. 610621

[3] A. Roman-Gonzalez, "Digital Images Analysis", Revista ECIPeru, vol. 9, № 1, 2012, pp. 61-68.

[4] J. Hyung-Sup, W. Joong-Sun, K. Myung-Ho, L. Yong-Woong, "Detection and Restoration of Defective Lines in the SPOT 4 SWIR Band", IEEE Transaction on Image Processing, 2010.

[5] B. S. Manjunath, W. Y. Ma; "Texture Features for Browsing and Retrieval of Image Data", IEEE Transaction on Pattern Analysis and Machine Intelligence, vol. 18, $\mathrm{N}^{\circ} 8$, August 1996, pp. 837-842.

[6] M. Campedel, E. Moulines, H. Maitre, M. Datcu; "Feature Selection for Satellite Image Indexing", ESA-EUSC: Image Information Mining - Theory and Application to Earth Observation - 2005 .
[7] M. Presuti; "La Matriz de Co-ocurrencia en la Clasificacion Multiespectral: Tutorial para la Ensenanza de Medidas Texturales en Cursos de Grado Universitario", $4^{\circ}$ Jornada de Educacao em Sensoriamento Remoto no Ambito do Mercosul, Agosto 2004, Brasil.

[8] D. Comaniciu \& P. Meer, (2002). Mean Shift A Robust Approach Toward Features Space Analysis, IEEE Transactions on Pattern analysis and Machine Intelligence, vol. $24, \mathrm{~N}^{\circ}$ 5, pp. 603-619.

[9] A. Roman-Gonzalez \& M. Datcu, (2011b). Data Cleaning: Approaches for Earth Observation Image Information Mining, ESAEUSC-JRC 2011 Image Information Mining: Geospatial Intelligence from Earth Observation Conference, Ispra, Italy, pp. 117120.

[10] A. Roman-Gonzalez \& M. Datcu, (2011a). Satellite Image Artifacts Detection Based on Complexity Distortion, IEEE International Geoscience and Remote Sensing Symposium (IGARSS 2011), Vancouver, Canada, pp. 1437-1440.

[11] A. Roman-Gonzalez \& M. Datcu, (2011a). Satellite Image Artifacts Detection Based on Complexity Distortion, IEEE International Geoscience and Remote Sensing Symposium (IGARSS 2011), Vancouver, Canada, pp. 1437-1440.

E-mail: avid.roman-gonzalez@ieee.org 